\title{
Predictable patterns and predictive skills of monsoon precipitation in Northern Hemisphere summer in NCEP CFSv2 reforecasts
}

\author{
Zhiyan Zuo $\cdot$ Song Yang $\cdot$ Zeng-Zhen Hu $\cdot$ \\ Renhe Zhang • Wanqiu Wang • \\ Bohua Huang • Fang Wang
}

Received: 27 December 2012/Accepted: 15 April 2013/Published online: 27 April 2013

(C) The Author(s) 2013. This article is published with open access at Springerlink.com

\begin{abstract}
The predictable patterns and predictive skills of monsoon precipitation in the Northern Hemisphere summer (June-July-August) are examined using reforecasts (1983-2010) from the National Center for Environmental Prediction Climate Forecast System version 2 (CFSv2). The possible connections of these predictable patterns with global sea surface temperature (SST) are investigated. The empirical orthogonal function analysis with maximized signal-to-noise ratio is used to isolate the predictable patterns of the precipitation for three regional monsoons: the Asian and Indo-Pacific monsoon (AIPM), the Africa monsoon (AFM), and the North America monsoon (NAM). Overall, the CFSv2 well predicts the monsoon precipitation patterns associated with El Niño-South Oscillation (ENSO) due to its good prediction skill for ENSO. For AIPM, two identified predictable patterns are an equatorial dipole
\end{abstract}

This paper is a contribution to the Topical Collection on Climate Forecast System Version 2 (CFSv2). CFSv2 is a coupled global climate model and was implemented by National Centers for Environmental Prediction (NCEP) in seasonal forecasting operations in March 2011. This Topical Collection is coordinated by Jin Huang, Arun Kumar, Jim Kinter and Annarita Mariotti.

\section{Z. Zuo $\cdot$ R. Zhang}

Chinese Academy of Meteorological Sciences, Beijing 100081, China

S. Yang $(\bowtie)$

Department of Atmospheric Sciences, Sun Yat-sen University, 123 West Xingang Road, Guangzhou 510275, Guangdong,

China

e-mail: yangsong3@mail.sysu.edu.cn

Z.-Z. Hu $\cdot$ W. Wang

NOAA's Climate Prediction Center, College Park, MD 20740,

USA pattern characterized by opposite variations between the equatorial western Pacific and eastern Indian Ocean, and a tropical western Pacific pattern characterized by opposite variations over the tropical northwestern Pacific and the Philippines and over the regions to its west, north, and southeast. For NAM, the predictable patterns are a tropical eastern Pacific pattern with opposite variations in the tropical eastern Pacific and in Mexico, the Guyana Plateau and the equatorial Atlantic, and a Central American pattern with opposite variations in the eastern Pacific and the North Atlantic and in the Amazon Plains. The CFSv2 can predict these patterns at least 5 months in advance. However, compared with the good skill in predicting AIPM and NAM precipitation patterns, the CFSv2 exhibits little predictive skill for AFM precipitation, probably because the variability of the tropical Atlantic SST plays a more important than ENSO in the AFM precipitation variation and the prediction skill is lower for the tropical Atlantic SST than the tropical Pacific SST.

Keywords Northern Hemisphere monsoons - Most predictable patterns - NCEP Climate Forecast System

\author{
B. Huang \\ Department of Atmospheric, Oceanic, and Earth Sciences, \\ George Mason University, Fairfax, VA 22030, USA \\ B. Huang \\ Center for Ocean-Land-Atmosphere Studies, Calverton, \\ MD 20705, USA \\ F. Wang \\ National Climate Center, CMA, Beijing 100081, China
}




\section{Introduction}

The progress of coupled ocean-atmosphere models and the corresponding data assimilation system makes seasonal climate predictions possible in the last decade or so (Wang et al. 2001; Palmer et al. 2004; Saha et al. 2006; Molteni et al. 2011). At the National Center for Environmental Prediction (NCEP), seasonal forecasts using the Climate Forecast System (CFS) have become operational since 2004 (Saha et al. 2006). The new version of the CFS (CFSv2) has been used in the operation since 2011. Compared with CFSv1, the CFSv2 represents a substantial change to all aspects of the forecast system including model components, data assimilation system and ensemble configuration. Recently, many efforts have been devoted to assessing CFSv2 products. These studies have reported prediction skill improvements in ENSO, the tropical Atlantic SST, global land precipitation, surface air temperature, and the Madden-Julian Oscillation in CFSv2 compared to CFSv1 (Yuan et al. 2011; Weaver et al. 2011; Jiang et al. 2012; Jiang et al. 2013; Hu et al. 2012a), as well as biases in the CFSv2 (Kumar et al. 2012; Kim et al. 2012; Liu et al. 2012).

Nevertheless, some aspects of CFSv2 prediction skill have not been fully investigated. For example, it is unclear what the prediction skills and predictable patterns of the precipitation are in monsoon regions in the CFSv2, although the CFSv1 showed capability of predicting the most dominant modes of Asian and Indo-Pacific summer precipitation several months ahead ( Yang et al. 2008; Liang et al. 2009; Yang et al. 2012). For the Northern Hemisphere summer, there are three well-known monsoon regions: the Asian and Indo-Pacific monsoon (AIPM; $40^{\circ} \mathrm{E}-180^{\circ} \mathrm{E}, 30^{\circ} \mathrm{S}-50^{\circ} \mathrm{N}$ ), the African monsoon $\left(\mathrm{AFM} ; 30^{\circ} \mathrm{W}-50^{\circ} \mathrm{E}, 5^{\circ} \mathrm{S}-20^{\circ} \mathrm{N}\right)$ and the Northern American monsoon (NAM; $120^{\circ} \mathrm{W}-30^{\circ} \mathrm{W}$, $10^{\circ} \mathrm{S}-50^{\circ} \mathrm{N}$ ) (Tang and Reiter 1984; Webster and Yang 1992; Rowell et al. 1995; Adams and Comrie 1997; Meehl and Arblaster 1998; Barlow et al. 1998; Wang and Ding 2008). Furthermore, the lead-time dependence of predictable patterns and prediction skills for seasonal precipitation in the three monsoon regions also need to be analyzed.

In this study, we address several issues about the monsoon precipitation for Northern Hemisphere summer in the CFSv2. We first identify the predictable patterns of AIPM, AFM and NAM precipitation. We then quantify the leadtime dependence of these predictable patterns and the possible influence of global SST. The coupled forecast system, the CFSv2 retrospective forecasts (called reforecasts thereafter) and observational data, as well as the analysis method, are described briefly in Sect. 2. Results are presented in Sect. 3, and a summary is provided in Sect. 4.

\section{Model, data and analysis methods}

The CFSv2 is a fully coupled climate system (Saha et al. 2012). It consists of the NCEP Global Forecast System at T126 resolution, the Geophysical Fluid Dynamics Laboratory Modular Ocean Model versions 4.0 coupled with a twolayer sea ice model, and the four-layer Noah land surface model. We analyze the CFSv2 reforecasts covering all 12 calendar months from 1983 to 2010 . These reforecasts, each of which is a 9-month integration, are an ensemble of 16 members initialized from the Climate Forecast System Reanalysis (CFSR; Saha et al. 2010), with initial dates before the 31th of the particular month used as the ensemble member for the next month. Reforecasts of 9 months were initiated from every 5 day and run from all 4 cycles of that day. The initial days vary from 1 month to another. A detail about the initial time can be found at http://cfs.ncep.noaa. gov/cfsv2.info/ (see file "Retrospective CFSv2 Forecast Data Information"). For summer (June-July-August, JJA) 0 -month lead (LM0), the initial conditions of 16, 21, 26, and 31 May are for June, and 15, 20, 25, and 30 June (July) are for July (August). For JJA 8-month lead (LM8), the initial conditions of 14, 19, 24, and 29 September in previous year are for June, and 13, 18, 23, and 28 October (November) in previous year are for July (August). The observed data used for model verification include the Climate Prediction Center Merged Analysis of Precipitation (Xie and Arkin 1997) and the improved extended reconstructed SST version2 (Smith and Reynolds 2004).

The main analysis tools applied in this study include the conventional empirical orthogonal function analysis (EOF) and the EOF with maximized signal-to-noise ratio (MSN EOF). For the conventional EOF analysis, we use ensemble mean of 16 members from the CFSv2 reforecasts. By design, the higher-ranked EOF mode accounts for the larger fraction of the total variance of the ensemble mean. However, due to the limited number of the ensemble, the ensemble mean actually still contains a substantial fraction of the internal atmospheric variability, which can be considered as unpredictable noise on seasonal time scale. For an ensemble forecast, the patterns of the internal variability can be estimated from the departures of individual members from their ensemble mean. To further eliminate the influences of the internal noise in the ensemble forecast, it is useful to apply MSN EOF, which isolates the most predictable patterns by maximizing the ratio of the variances of the ensemble mean and within-ensemble deviations (Allen and Smith 1997; Venzke et al. 1999; Huang 2004). By definition, the pattern described by the MSN EOF mode is predictable if the forced response is consistent and matches observations significantly. The MSN EOF has been successfully used in identifying the most 
predictable patterns of SST in the tropical Atlantic (Hu and Huang 2007a), Asian summer monsoon rainfall (Liang et al. 2009), and East China Mei-yu (Gao et al. 2011) in CFSv1 reforecasts.

\section{Results}

Considering the pronounced precipitation variations in the three monsoon regions, the focus of this study is to investigate the predictable patterns of monsoon precipitation and their prediction skills in the CFSv2 reforecasts. We first analyze the leading modes of observed precipitation anomalies in the three monsoon regions, then compare these observed modes with those in the CFSv2 reforecasts with different lead time to identify the predictable precipitation patterns and their predictability and prediction. Also, we will explore the possible connection of these predictable patterns with global SST, particularly ENSO.

\subsection{Leading patterns of observed AIPM, AFM, and NAM precipitation}

Figure 1 shows the first and second modes of conventional EOF in observed AIPM, AFM, and NAM precipitation and their associated principal components (PCs). For AIPM precipitation (Fig. 1a), the first and second EOF modes explain 23.0 and $13.3 \%$ of the total variance, respectively. The EOF1 is an equatorial dipole pattern, showing opposite variations in the equatorial central-eastern Indian Ocean and Indonesia and in the eastern Bay of Bengal to the Philippines. The main variability in EOF2 is in the tropical western Pacific, with opposite variations over the tropical northwestern Pacific and the Philippines and over the regions to its west, north, and southeast. Thus, it is called tropical western Pacific pattern. Noticeably, this mode also shows coherence with the rainfall anomalies in the western Indian Ocean. Both the PC1 and the PC2 show obvious interannual variability. The simultaneous correlations between the PC1 and Niño3.4 SST are 0.84, exceeding the $99.9 \%$ confidence level. We will discuss this relationship in detail later.

Figure $1 \mathrm{~b}$ shows the first and second EOF modes and corresponding PCs of the AFM precipitation. The two modes together explain more than $43 \%$ of the total variance, with $26.6 \%$ for the first mode and $16.7 \%$ for the second mode. The EOF1 represents out-of-phase variations in two precipitation centers in Africa, one around the western coast near $8^{\circ} \mathrm{N}$ and the other near the eastern Guinean coast region. It is called western coast dipole pattern. The PC1 exhibits a downward tendency, suggesting a drying trend in the west coast near $8^{\circ} \mathrm{N}$ and a wetting trend near the eastern Guinean coast and Sahel. The EOF2 displays an in-phase precipitation variation in the northeastern Atlantic and the Gulf of Guinea, and is referred to as northeastern Atlantic pattern. Both patterns seem to be related to the anomalous displacement in the location of the eastern Atlantic intertropical convergence zone (ITCZ) in boreal summer. Compared with PC1, the PC2 shows more robust interannual fluctuations but smaller decadal variations and trends.

Figure 1c documents the first two EOF modes and corresponding PCs of the NAM precipitation. It is noted that above $46 \%$ of the total variance is explained by the two EOF modes, suggesting that the precipitation variability in NAM is more concentrated into the first two leading modes, compared with that in AIPM and AFM. The EOF1 reflects opposite variations between a zonal belt north of equator and south of $10^{\circ} \mathrm{N}$ over the eastern Pacific and a broader area in Mexico, the Caribbean Sea, the Guyana Plateau and the equatorial Atlantic. We refer this mode to as the tropical eastern Pacific pattern. The PC1 shows mainly interannual variation with an abrupt fluctuation in 1996/1997. The EOF2 shows opposite variations between the regions in the eastern Pacific east of $110^{\circ} \mathrm{W}$, the Caribbean Sean and the tropical North Atlantic and in the surrounding regions, including the tropical North Pacific in $110^{\circ}-120^{\circ} \mathrm{W}$, the eastern coast of North America and the Amazon Plains. We name this mode the Central American pattern. Compared with the PC1, the interannual variations in the $\mathrm{PC} 2$ are more apparent.

\subsection{Most predictive patterns of AIPM, AFM, and NAM precipitation in CFSv2}

\subsubsection{AIPM}

Figure 2 shows the conventional EOF1s and the associated PC1s of the CFSv2 ensemble-mean AIPM precipitation anomalies for different lead times. The spatial distribution patterns are similar for different lead times (Fig. 2a, c, e, g, i). Clearly, compared with the EOF1 of observation (Fig. 1a), the equatorial dipole pattern is captured by the CFSv2. The major bias of the CFSv2 patterns compared with the observed EOF1 (Fig. 1a) is the variations over the equatorial central Indian Ocean. Coherent variations appear to its surrounding regions in observation, but opposite variations are seen in the CFSv2 reforecasts. The above equatorial dipole pattern and the major bias generally maintain as lead time increases.

Although the ensemble mean can largely eliminate the atmospheric internal variability (noise) in the CFSv2 reforecasts, the noise level in the ensemble mean may still be non-negligible, because 16 members may not be a statistically sufficient sample size. The dash lines shown in the right panels of Fig. 2 are the projections of the individual 
Fig. 1 First and second conventional EOF modes of observed precipitation

$(\mathrm{mm} /$ day) and the associated principal components (red lines) over a AIPM, b AFM, and c NAM. Only contours 1 and -1 are plotted
EOF1\&EOF2 CMAP JJA Prec.

(a) AIPM

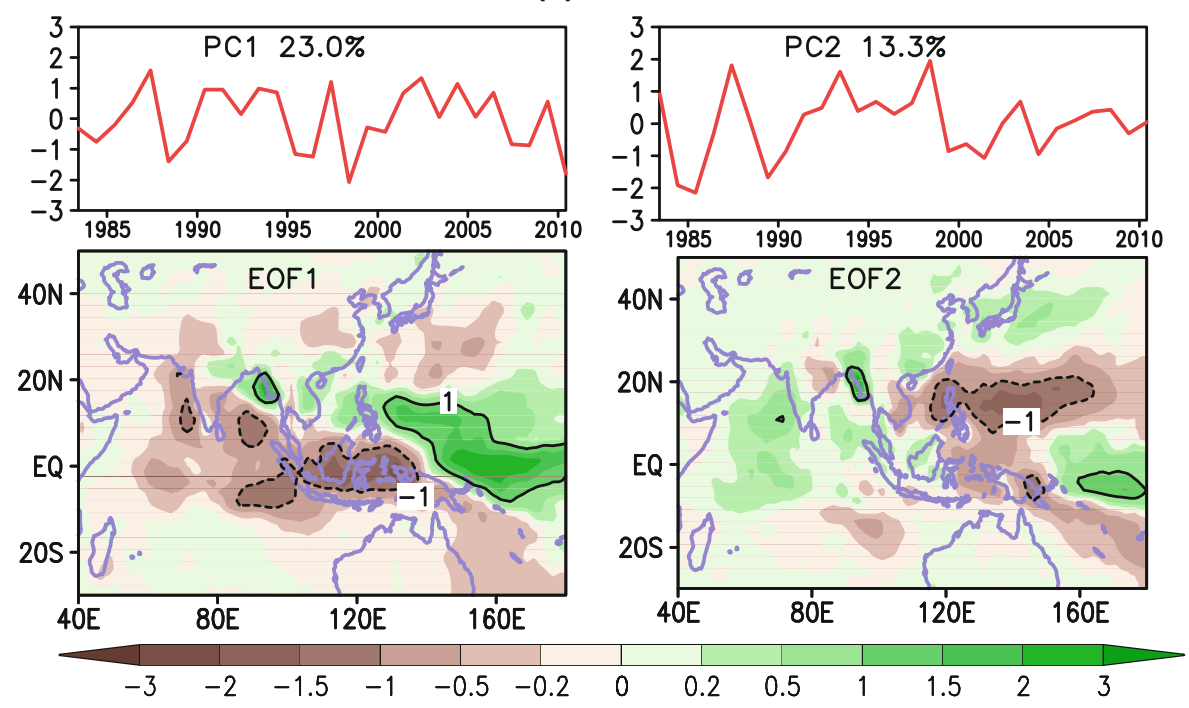

(b) AFM

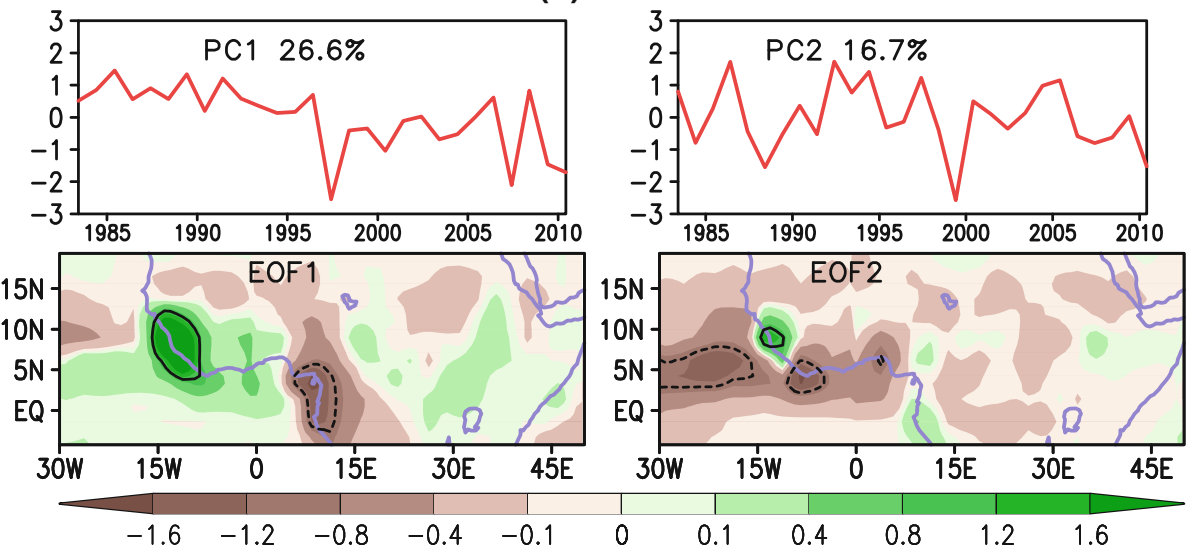

(c) NAM

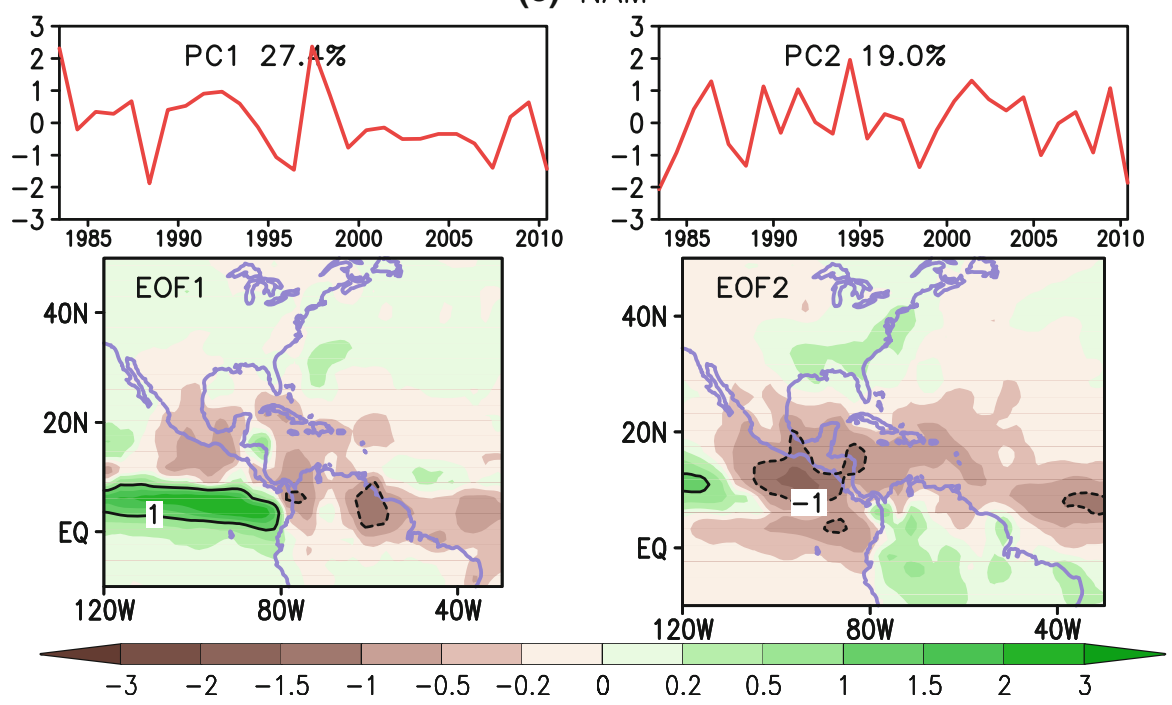


Fig. 2 First conventional EOF modes of the CFSv2 reforecast ensemble mean precipitation ( $\mathrm{mm} /$ day) over AIPM for lead months of $0,2,4,6$, and 8 . In the right panels, the solid black lines are the PCs of ensemble means. The solid red lines and dashed black lines represent the PCs that are computed by projecting the observed precipitation and individual members of the CFSv2 AIPM precipitation upon the conventional EOF1, respectively. Only contours 1 and -1 are plotted

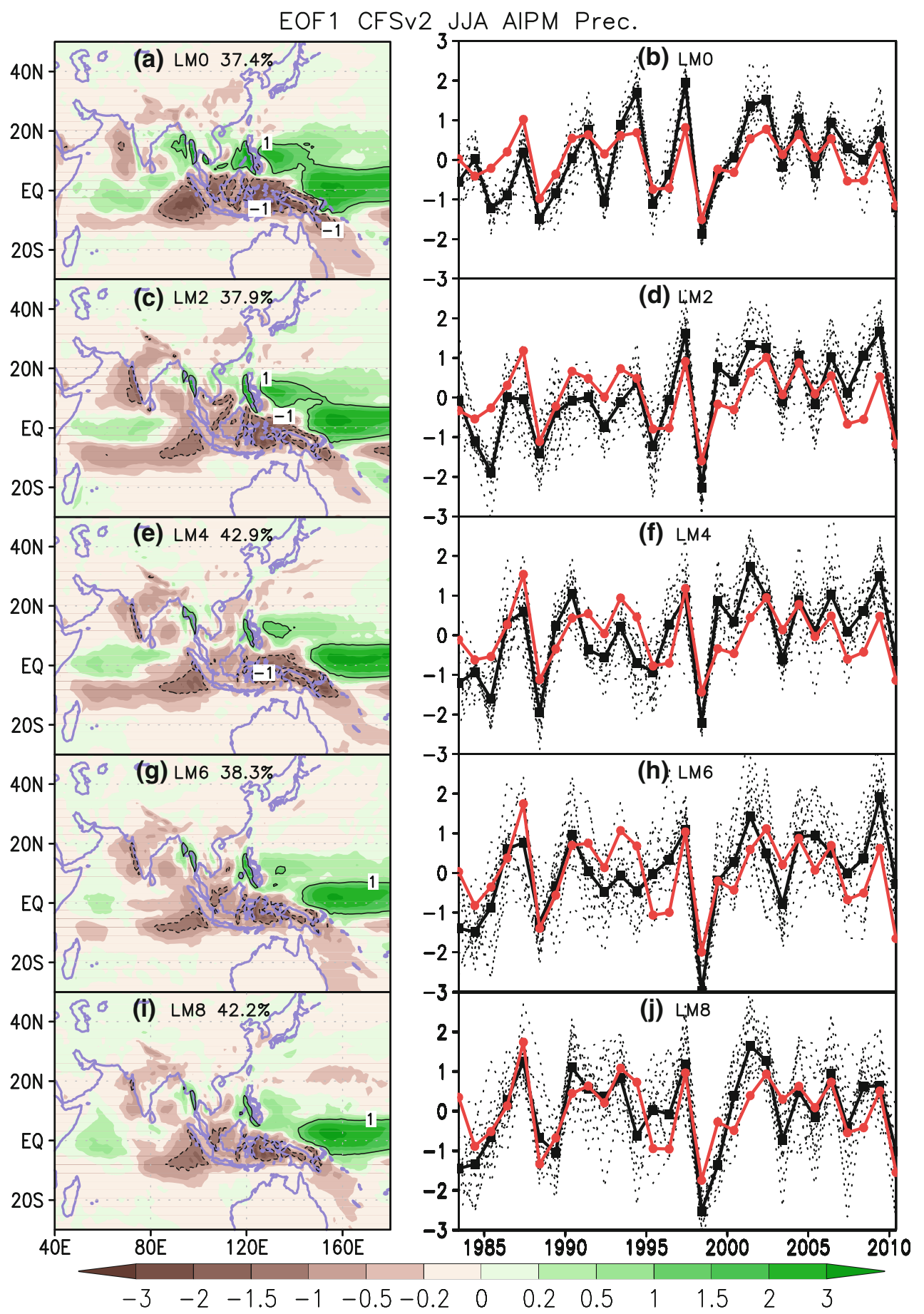

ensemble members onto these EOF1s. It is noted that the spreads become larger for longer lead months. Thus, it arguably reflects the uncertainty associated with the leading modes of ensemble-mean variations in the CFSv2 reforecast, because the sampling noise may be pronounced for the small ensemble size. As mentioned in Sect. 2, the MSN EOF is an effective technique to isolate the signal (predictable pattern) from noise-embedded variations, such as the CFSv2 reforecasts. Figure 3 is the MSN EOF1s and the corresponding PC1s, which explain at least $35 \%$ of the total variance for all different leads. For lead months 0-4 (LM0-LM4), the MSN EOF1s are similar to the conventional EOF1s (Fig. 2). The main discrepancies between the two methods are seen from the corresponding PCs. It is noted that the spreads among ensemble members in the MSN PC1s (right panels of Fig. 3) are smaller than those in the conventional PC1s (right panels of Fig. 2). (The correlations among ensemble members in the MSN EOF1 are 
Fig. 3 First MSN EOF modes of the CFSv2 reforecast precipitation $(\mathrm{mm} /$ day) over AIPM for lead months of $0,2,4$, 6 , and 8 . In the right panels, the solid black lines and dashed black lines are the PCs of ensemble means and individual members, respectively. The solid red lines represent the PCs that are computed by projecting the observed precipitation upon the MSN EOF1. Only contours 1 and -1 are plotted

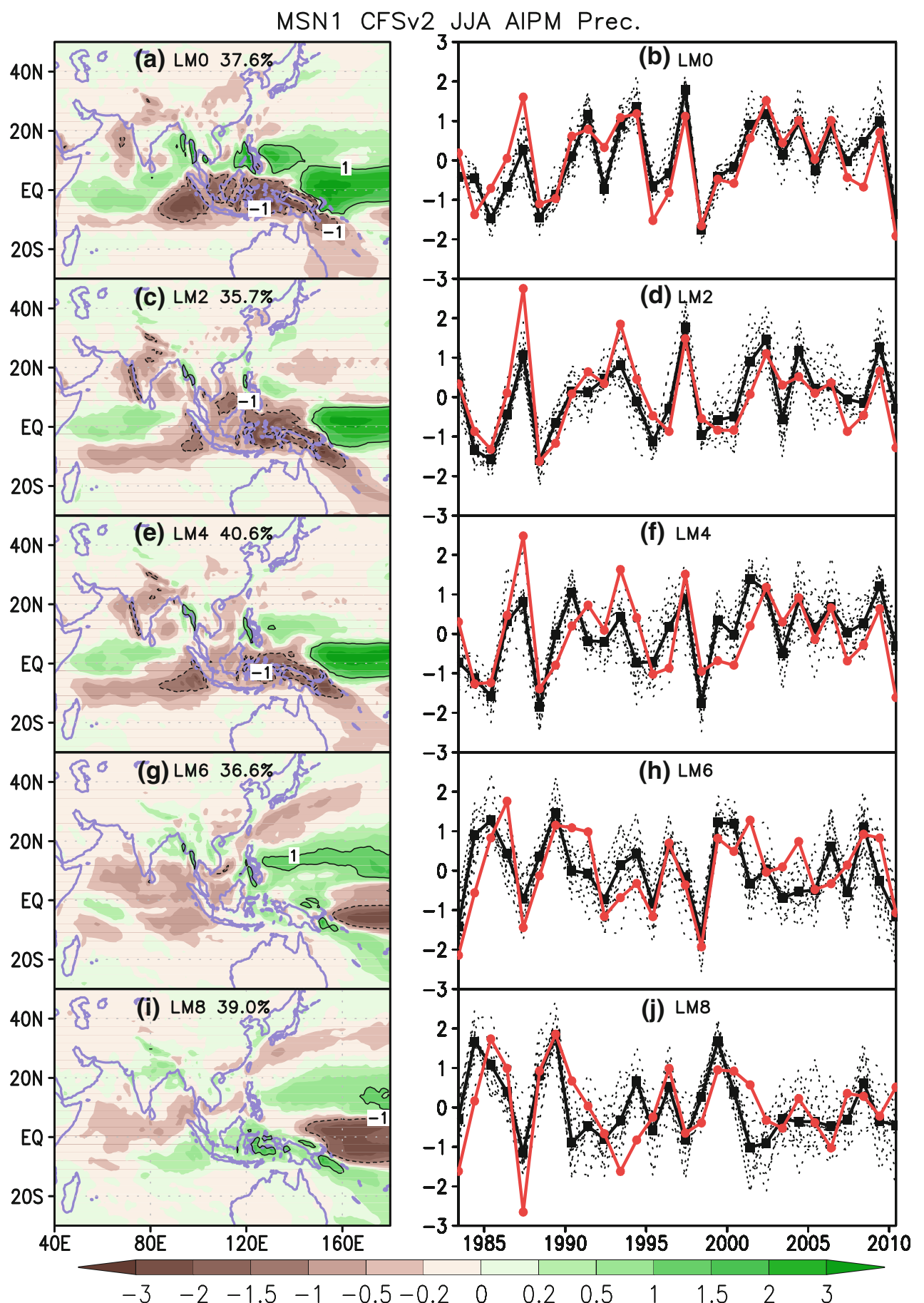

higher than those in the conventional EOF1s as shown in Fig. 5a). Moreover, the time series derived from observations are more similar to the ensemble mean in the MSN EOF1s compared with those in the conventional EOF1s for LM0-5. (The correlations between the time series derived from observations and the ensemble means in the MSN EOF1 are higher than those in the conventional EOF1s; not shown). The discrepancies between the conventional EOF1s and the MSN EOF1s become larger when the leads are longer than 4 months. The MSN EOF1s and PC1s of AIPM precipitation for LM6 and LM8 have little similarity to the corresponding conventional EOF1s and PC1s, but they are similar to the EOF2 and PC2 in the observation (The correlations between MSN PC1s and observed PC2s are significant for LM5-8 as shown in Table 1). This feature implies that with the increase in lead time, the spreads among ensemble members become larger and, as a result, the most predictable patterns also change. 
Table 1 MSN EOFs and correlations for AIPM precipitation

\begin{tabular}{|c|c|c|c|c|c|c|c|c|c|}
\hline & LM0 & LM1 & LM2 & LM3 & LM4 & LM5 & LM6 & LM7 & LM8 \\
\hline MSN1: $\sigma_{M}^{2} / \sigma_{N}^{2}$ & 6.20 & 6.28 & 3.56 & 3.97 & 2.91 & 2.26 & 2.04 & 2.15 & 2.08 \\
\hline MSN2: $\sigma_{M}^{2} / \sigma_{N}^{2}$ & 2.48 & 2.58 & 2.56 & 1.95 & 1.87 & 1.61 & 1.50 & 1.66 & 1.54 \\
\hline MSN1: $R_{\text {mean }, p c 1}$ & 0.79 & 0.79 & 0.73 & 0.67 & 0.67 & 0.33 & 0.04 & 0.50 & 0.49 \\
\hline MSN1: $R_{\text {mean }, p c 2}$ & 0.02 & 0.10 & 0.28 & 0.26 & 0.05 & 0.49 & 0.62 & 0.45 & 0.49 \\
\hline MSN2: $R_{\text {mean,pc2 }}$ & 0.65 & 0.64 & 0.51 & 0.48 & 0.56 & 0.35 & 0.05 & 0.44 & 0.32 \\
\hline MSN2: $R_{\text {mean }, p c 1}$ & 0.11 & 0.13 & 0.12 & 0.25 & 0.13 & 0.50 & 0.62 & 0.50 & 0.53 \\
\hline
\end{tabular}

The 1st and 2nd rows are ratios of ensemble-mean and within-ensemble variances in MSN EOF1 (MSN1) and MSN EOF2 (MSN2), respectively. The 3rd and 4th rows are the correlation coefficients between MSN PC1 and the observed PC1 and PC2, respectively. The 5th and 6th rows are the correlation coefficients between MSN PC2 and the observed PC2 and PC1, respectively. Bold numbers in the 1st and 2nd rows are above the $95 \%$ confidence level $(F$ test). The bold numbers in the 3rd-4th (5th-6th) rows are the correlation coefficients above the $95 \%$ confidence level (Student $t$ test) in the case of the significant ratios in 1 st (2nd) rows

Figure 4 shows the MSN EOF2s and the corresponding PC2s of AIPM precipitation. The second predictable patterns explain at least $15 \%$ of the total variance for all leads. For LM0-LM4, the MSN EOF2s well reproduce the observed EOF2 patterns (Fig. 1a). However, for leads longer than LM4, the patterns (Fig. 4g, i) are similar to the observed first and second EOFs to some extent (Fig. 1a).

Figure 5a shows the averaged pattern of correlation coefficients among the 16 ensemble members in the conventional EOFs and the MSN EOFs of AIPM precipitation for different leads. Clearly, the correlations among ensemble members in the MSN EOF1s are higher than those in the conventional EOF1s, implying the advantage of MSN EOF in isolating the predictable patterns than the conventional EOFs [This feature also appears for AFM and NAM precipitation (Figs. 7a, 10a)]. Also, it is noted that although the correlations decrease when lead time increases, almost all the correlations are larger than 0.6, meaning that both first and second modes of the MSN EOF may have good predictability. In addition, the correlations of the MSN EOF1 are larger than those in the MSN EOF2 for the same leads, indicating that the MSN EOF1 may have higher predictability than the MSN EOF2. We also calculated the correlations between the projecting PCs, computed by projecting the observed precipitation upon the MSN EOF modes, and ensemble mean PCs (Fig. 5b). Clearly, the correlations in both MSN EOF1s and MSN EOF2s are significant, although they decrease with lead time, indicating that the MSN EOF1s and the MSN EOF2s match observations fairly well. Additionally, the correlations in MSN EOF1s are higher than those in MSN EOF2s for the same leads except for LM7-8. Overall, the results in Fig. $5 \mathrm{~b}$ are consistent with those in Fig. 5a, confirming that both the MSN EOF1 and the MSN EOF2 may be predictable, particularly for short leads, which is further verified by examining the variance ratio between the ensemble mean and the individual member departure from the ensemble mean.

The ratios of ensemble-mean and within-ensemble variances in the first two MSN EOFs in AIPM are shown in Table 1 . It is easy to verify that $\sigma_{M}^{2} / \sigma_{N}^{2} \rightarrow F_{m-1, m-1}^{0.05}=$ $1.91, \sigma_{M}^{2}$ and $\sigma_{N}^{2}$ are variances of the ensemble-mean and the within-ensemble variances, respectively. The $\sigma_{M}^{2} / \sigma_{N}^{2}>F_{0.05}$ suggests that the sign of the individual ensemble members is the same with a certain confidence level. Namely, the response is consistent. It can be seen that the variance ratios are significant for the MSN EOF1 in all lead months and for the MSN EOF2 in LM0-LM3 (1st-2nd rows, Table 1). The coefficients of correlation between ensemble-mean PCs and observed PCs document that the MSN EOF1 show significant relationship with observed EOF1 for LM0-LM4 and LM7-8 and with observed EOF2 for LM5-LM8, whereas the MSN EOF2 shows significant relationship with observed EOF2 for LM0-LM4 and with observed EOF1 for LM5-LM8 (3rd-6th rows, Table 1). The equatorial dipole pattern in MSN EOF1 for LM0-LM4, and the tropical western Pacific pattern in MSN EOF2 for LM0-3 and in MSN EOF1 for LM5-6, exhibit consistent responses and significant correlation with observations, suggesting that these patterns are predictable patterns. Although the responses in MSN PC1s for LM7-8 are consistent and show significant correlations with observed PC1s and PC2s, the tropical western Pacific patterns for LM5-8 are predictable patterns because the MSN EOF1s for LM7-8 match the tropical western Pacific pattern better than the equatorial dipole pattern (Figs. 1a, 3i). Overall, the equatorial dipole pattern is the most predictable pattern, and the CFSv2 can predict its evolution in leads by 5 months. The tropical western Pacific pattern is the second most predictable pattern for LM0-LM3 and the only predictable pattern for LM5-LM8. In general, the CFSv2 can capture this pattern 9 months ahead. 
Fig. 4 Second MSN EOF modes of the CFSv2 reforecast precipitation $(\mathrm{mm} /$ day) over AIPM for lead months of $0,2,4$, 6 , and 8 . In the right panels, the solid black lines and dashed black lines are the PCs of ensemble means and individual members, respectively. The solid red lines represent the PCs that are computed by projecting the observed precipitation upon the MSN EOF2. Only contours 1 and -1 are plotted

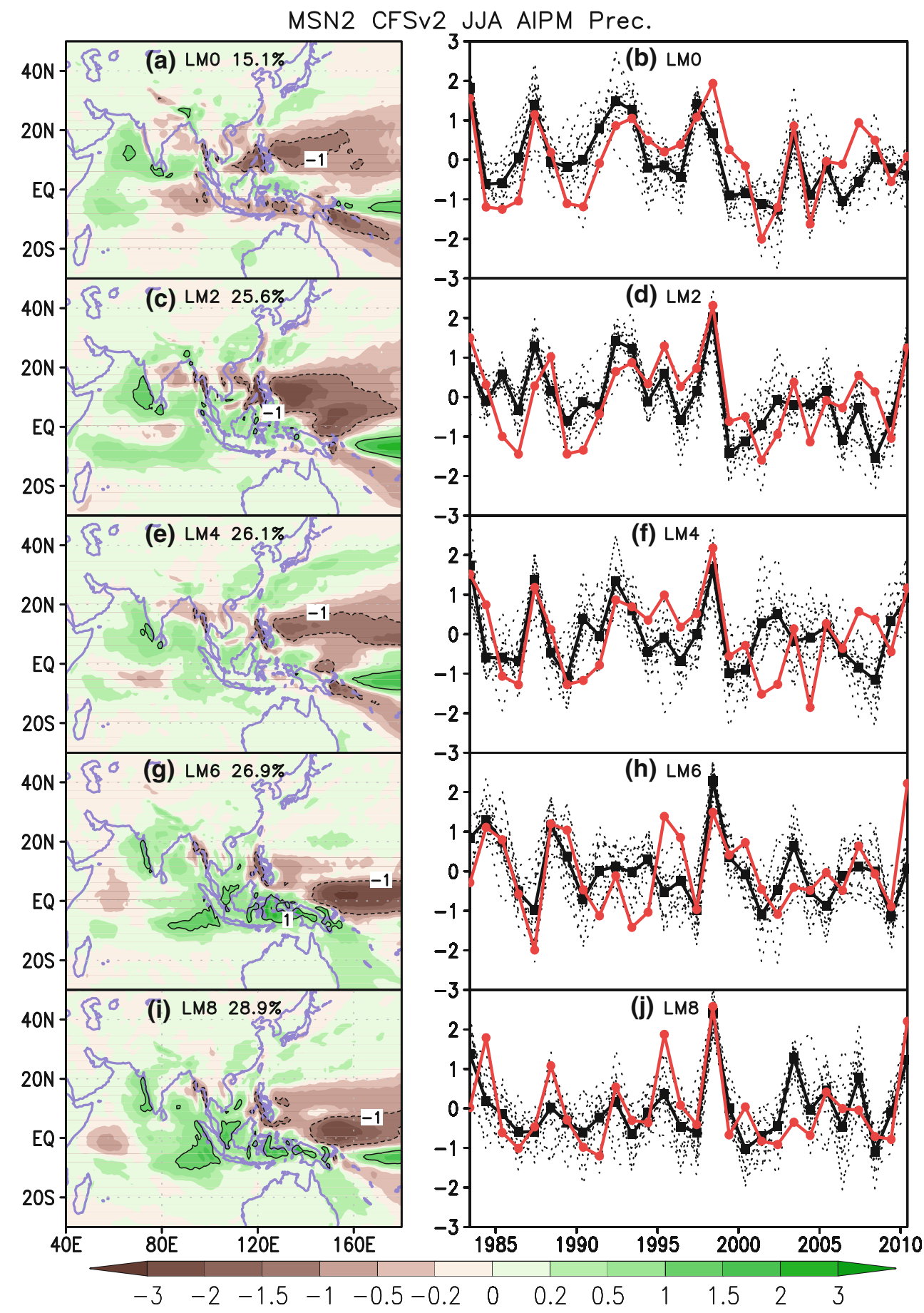

\subsubsection{AFM}

Figure 6 displays the MSN EOF1s and the corresponding PC1s of AFM precipitation for different leads. For the leads less than 3 months (Fig. 6a, c), the MSN EOF1 shows in-phase variations in the tropical North Atlantic with maximum anomalies near $5^{\circ} \mathrm{N}$, which is similar to the North Atlantic pattern displayed in the observed EOF2 mode (Fig. 1b). For LM4-LM8, the patterns of MSN EOF1
(Fig. 6e, g, i) are quite different from those of the observed EOF1 and EOF2 (Fig. 1b). The MSN PC1 exhibits large spreads among the 16 ensemble members for lead time longer than 2 months. Compared with the AIPM (Fig. 3), the spread is much larger in the AFM (Fig. 6), implying the difference in predictability between the two precipitation patterns. Moreover, the observation-projected PCs (red lines) shows different variations from the ensemble mean MSN PC1 except for LM0 (black solid lines), suggesting 
Fig. 5 a Averaged pattern correlation coefficients among ensemble members in conventional EOF1 (short dashed lines), MSN EOF1 (solid lines), and MSN EOF2 (long dashed lines) of AIPM. b Correlation coefficients between ensemble mean PCs and projecting PCs (computed by projecting the observed precipitation upon the MSN EOF modes) for MSN PC1 (solid lines) and MSN PC2 (dashed lines) of AIPM. The dot black lines denote the correlation coefficients at the $95 \%$ confidence level (Student $t$ test) (a) Cor. coef. among ensemble members for AIPM Prec.

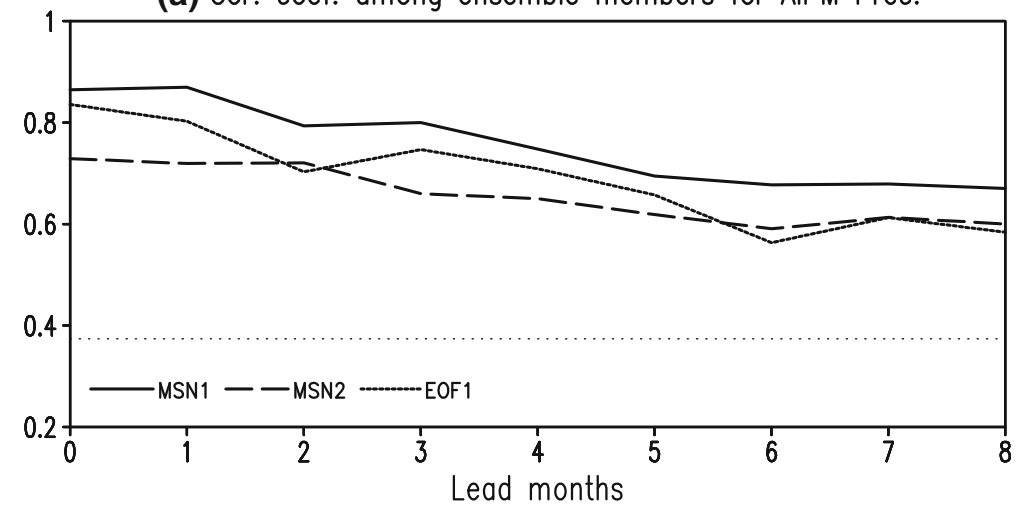

(b) Cor. coef. between Ensemble means and. proj. CMAP for AIPM Prec.

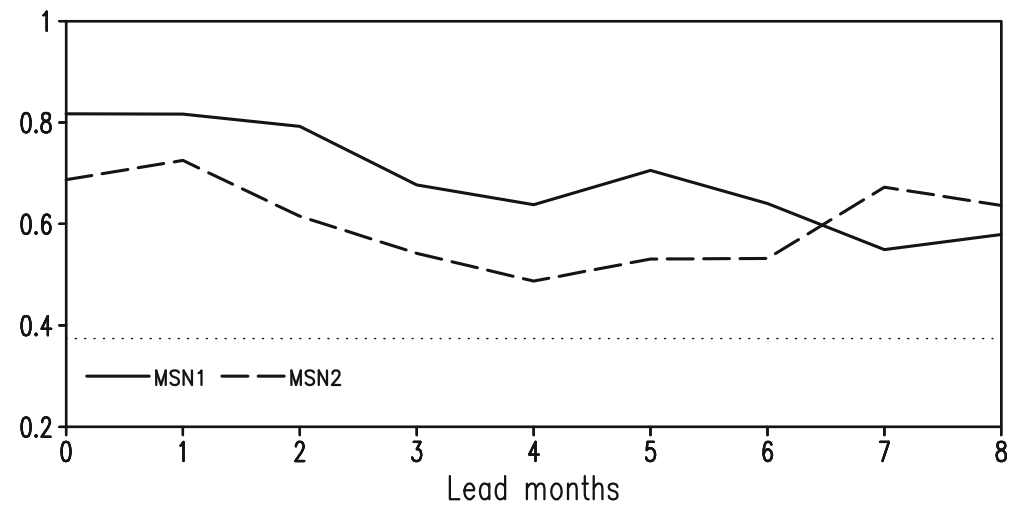

an inconsistency between observations and the CFSv2 reforecasts.

The coefficients of pattern correlation among ensemble members in the AFM MSN EOF1 and EOF2 (Fig. 7a) are smaller than those in AIPM (Fig. 5a) for all leads. In addition, in AFM, the coefficients of correlation between the projecting PCs and the PCs of ensemble mean in both MSN PC1 and MSN PC2 are insignificant for all leads except for marginally significant correlations for LM0 and LM7 in the MSN PC1 (Fig. 7b), whereas they are significant for all leads in AIPM (Fig. 5b). Thus, both the spreads among individual members and the discrepancy between observations and CFSv2 reforecasts in precipitation anomaly patterns in AFM are considerably larger than those in AIPM, suggesting a lower predictability in AFM than in AIPM.

Consistent with the correlations shown in Fig. 7, the ratios of ensemble-mean and within-ensemble variances in the AFM MSN EOF1 for LM3-LM8 and in the AFM MSN EOF2 for LM0-LM8 are insignificant except in the AFM MSN EOF1 for leads less than LM2 (1st-2nd rows, Table 2), suggesting that the CFSv2 only exhibits consistent responses in the MSN EOF1 for LM0-LM2. Moreover, for these modes with consistent responses, their significant correlations with observations only exist between ensemble mean MSN PC1 for LM0 and observed
PC2 (3rd-6th rows, Table 2), indicating that the observed pattern evolutions are not captured by the CFSv2 in general. Overall, the North Atlantic pattern is the only predictable pattern in AFM and the CFSv2 can predict it only 1 month in advance. For the western coast dipole pattern, the leading pattern in observations, the CFSv2 shows little predictability, and thus it is not shown and discussed here.

\subsubsection{NAM}

Figure 8 shows the MSN EOF1s and the corresponding PC1s of NAM precipitation for different lead times. For LM0-LM4, the MSN EOF1 captures the observed tropical eastern Pacific pattern to some extent. However, the negative loadings over eastern Pacific around $10^{\circ} \mathrm{N}$, north of South America, and the equatorial Atlantic in MSN EOF1 are much larger than those in observations (Fig. 1c). For LM6 and LM8, the MSN EOF1 is similar to the observed subtropical eastern Pacific pattern (Fig. 1c), though with some differences in details. The MSN EOF2 in NAM for LM0-LM4 captures the observed Central American pattern quite well (Fig. 9), which is better than that in the MSN EOF1 for LM6-LM8. The excessively strong (weak) negative loadings over the subtropical Pacific in $110^{\circ}-$ $120^{\circ} \mathrm{W}$ (the Amazon Plains) in the MSN EOF1 for LM6LM8 become realistic and consistent with observations in 
Fig. 6 First MSN EOF modes of the CFSv2 reforecast precipitation $(\mathrm{mm} /$ day) over AFM for lead months of $0,2,4$, 6 , and 8 . In the right panels, the solid black lines and dashed black lines are the PCs of ensemble means and individual members, respectively. The solid red lines represent the PCs that are computed by projecting the observed precipitation upon the MSN EOF1. Only contours 1 and -1 are plotted

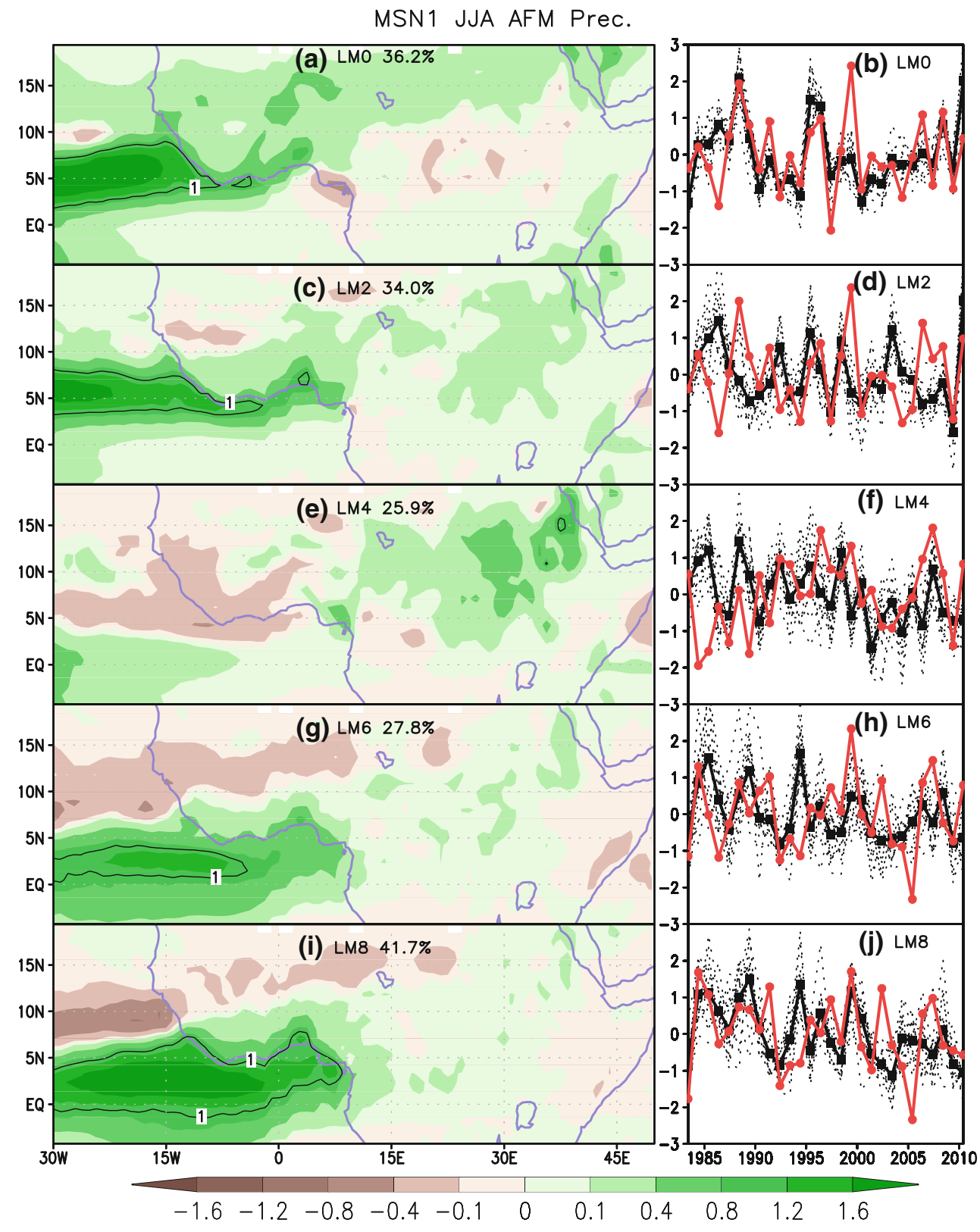

the MSN EOF2 for LM0-LM4. The MSN EOF2 for LM6-8 is similar to the MSN EOF1 for LM0-LM4.

Consistent with the small spreads among the 16 ensemble members in the NAM MSN PC1s and PC2s (Figs. 8, 9, right panels), the pattern correlations among ensemble members in the NAM MSN EOFs for all leads are significant (Fig. 10a). The correlation coefficients between projected PCs and ensemble means PCs in the NAM MSN EOF2 are significant for all leads (Fig. 10b). However, the coefficients in the NAM MSN EOF1 are significant for LM0-LM2 and LM6-LM8, marginally significant for LM3-LM4, and insignificant for LM5 (Fig. 10b). That is, although the MSN EOF1 for LM5 is still the leading pattern (exceeding $37.7 \%$ of total variance) in the CFSv2 reforecasts, the discrepancy between modeled pattern and observed pattern corresponds to large disagreement between the ensemble mean PC and the projected PC.

The ratios of ensemble-mean and within-ensemble variances in the NAM MSN EOF1 for all leads and in the NAM MSN EOF2 for LM0-LM3 and LM5 are significant (1st-2nd rows, Table 3), suggesting that these modes and their evolution may be predictable. The ensemble-mean MSN PC1s have significant correlations with the observed PC1 for LM0-LM4 and with observed PC2 for LM5-LM8 (3rd-6th rows, Table 3). For the MSN PC2, the ensemble means have significant correlations with the observed PC2 for LM0-LM3 and with the observed PC1 for LM5. In 
Fig. 7 a Averaged pattern correlation coefficients among ensemble members in conventional EOF1 (short dashed lines), MSN EOF1 (solid lines), and MSN EOF2 (long dashed lines) of AFM. b Correlation coefficients between ensemble mean PCs and projecting PCs (computed by projecting the observed precipitation upon the MSN EOF modes) for MSN PC1 (solid lines) and MSN PC2 (dashed lines) of AFM. The dot black lines denote the correlation coefficients at the $95 \%$ confidence level (Student $t$ test) (a) Cor. coef. among ensemble members for AFM Prec.

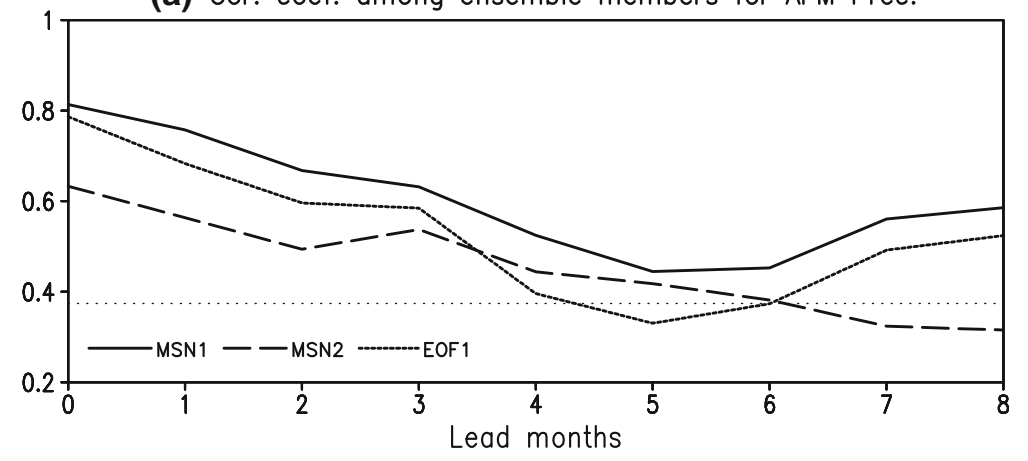

(b) Cor. coef. between Ensemble means and. proj. CMAP for AFM Prec.

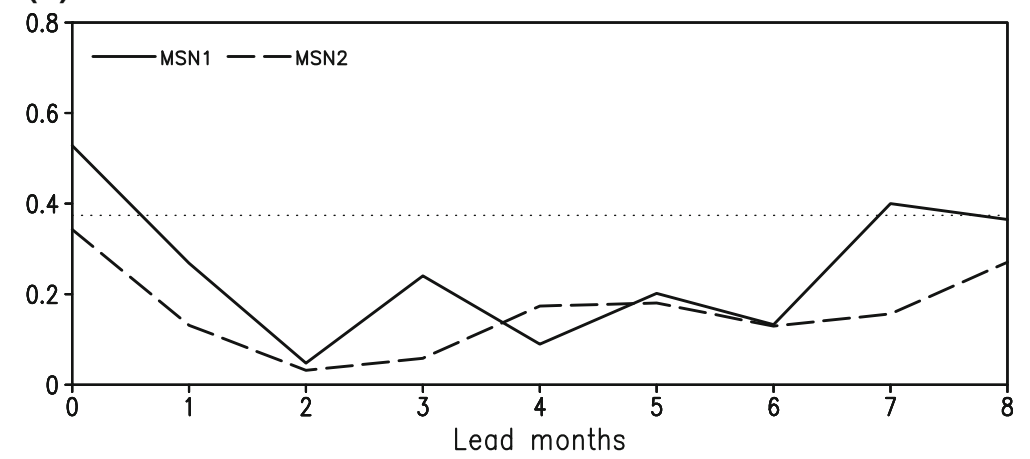

Table 2 MSN EOFs and correlations for AFM precipitation

\begin{tabular}{llllllllll}
\hline & LM0 & LM1 & LM2 & LM3 & LM4 & LM5 & LM6 & LM7 & LM8 \\
\hline MSN1: $\sigma_{M}^{2} / \sigma_{N}^{2}$ & $\mathbf{4 . 0 9}$ & $\mathbf{2 . 9 3}$ & $\mathbf{1 . 9 9}$ & 1.73 & 1.14 & 0.87 & 0.85 & 1.30 & 1.46 \\
MSN2: $\sigma_{M}^{2} / \sigma_{N}^{2}$ & 1.74 & 1.33 & 1.01 & 1.20 & 0.83 & 0.75 & 0.65 & 0.53 & 0.53 \\
MSN1: $R_{\text {mean,pc1 }}$ & 0.16 & 0.08 & 0.15 & 0.07 & 0.25 & 0.28 & 0.48 & 0.55 & 0.44 \\
MSN1: $R_{\text {mean,pc2 }}$ & $\mathbf{0 . 5 0}$ & 0.29 & 0.09 & 0.17 & 0.03 & 0.09 & 0.11 & 0.18 & 0.13 \\
MSN2: $R_{\text {mean,pc2 }}$ & 0.22 & 0.06 & 0.08 & 0.11 & 0.10 & 0.09 & 0.10 & 0.21 & 0.34 \\
MSN2: $R_{\text {mean,pc1 }}$ & 0.12 & 0.07 & 0.23 & 0.29 & 0.15 & 0.40 & 0.05 & 0.06 & 0.00 \\
\hline
\end{tabular}

See Table 1 footnote

other words, the CFSv2 can predict the observed tropical eastern Pacific pattern for LM0-LM5, and the observed Central American pattern for all leads except LM4.

\subsection{Impact of SST on the precipitation patterns in AIPM, AFM and NAM}

Figure 11 shows the correlations between JJA SST and the observed PC1 and PC2 shown in Fig. 1. The observed PC1 of AIPM precipitation (Fig. 11a) is connected with a central Pacific El Niño-like SST anomaly pattern with significant positive correlation in the central and eastern tropical Pacific and negative correlation in the western tropical Pacific, consistent with the central Pacific El Niño composite pattern shown in $\mathrm{Hu}$ et al. (2012b). The simultaneous correlation coefficient is 0.84 between the observed
PC1 and Niño 3.4 SST. It is thus suggested that ENSO is the dominant factor of the most predictable pattern in AIPM precipitation, agreeing with Liang et al. (2009). For the observed PC2 of AIPM precipitation, significant correlations are negative and mainly in the northern Indian Ocean and the tropical eastern Pacific (Fig. 11b), suggesting that both the Indian Ocean and ENSO play a role in this predictable pattern. Indeed, the EOF2 in AIPM precipitation (Fig. 1a) is very similar to the spatial distribution of the regression of observed precipitation onto broad-scale Asian monsoon circulation measured by the Webster-Yang index (WYI) (Lau et al. 2000). The correlation coefficient $(0.67)$ between the PC2 and WYI significantly exceeds the $99.9 \%$ confidence level.

For the observed PC1 of AFM precipitation, negative correlations prevail in almost the whole domain 
Fig. 8 First MSN EOF modes of the CFSv2 reforecast precipitation $(\mathrm{mm} /$ day) over NAM for lead months of $0,2,4$, 6 , and 8 . In the right panels, the solid black lines and dashed black lines are the PCs of ensemble means and individual members, respectively. The solid red lines represent the PCs that are computed by projecting the observed precipitation upon the MSN EOF1. Only contours 1 and -1 are plotted

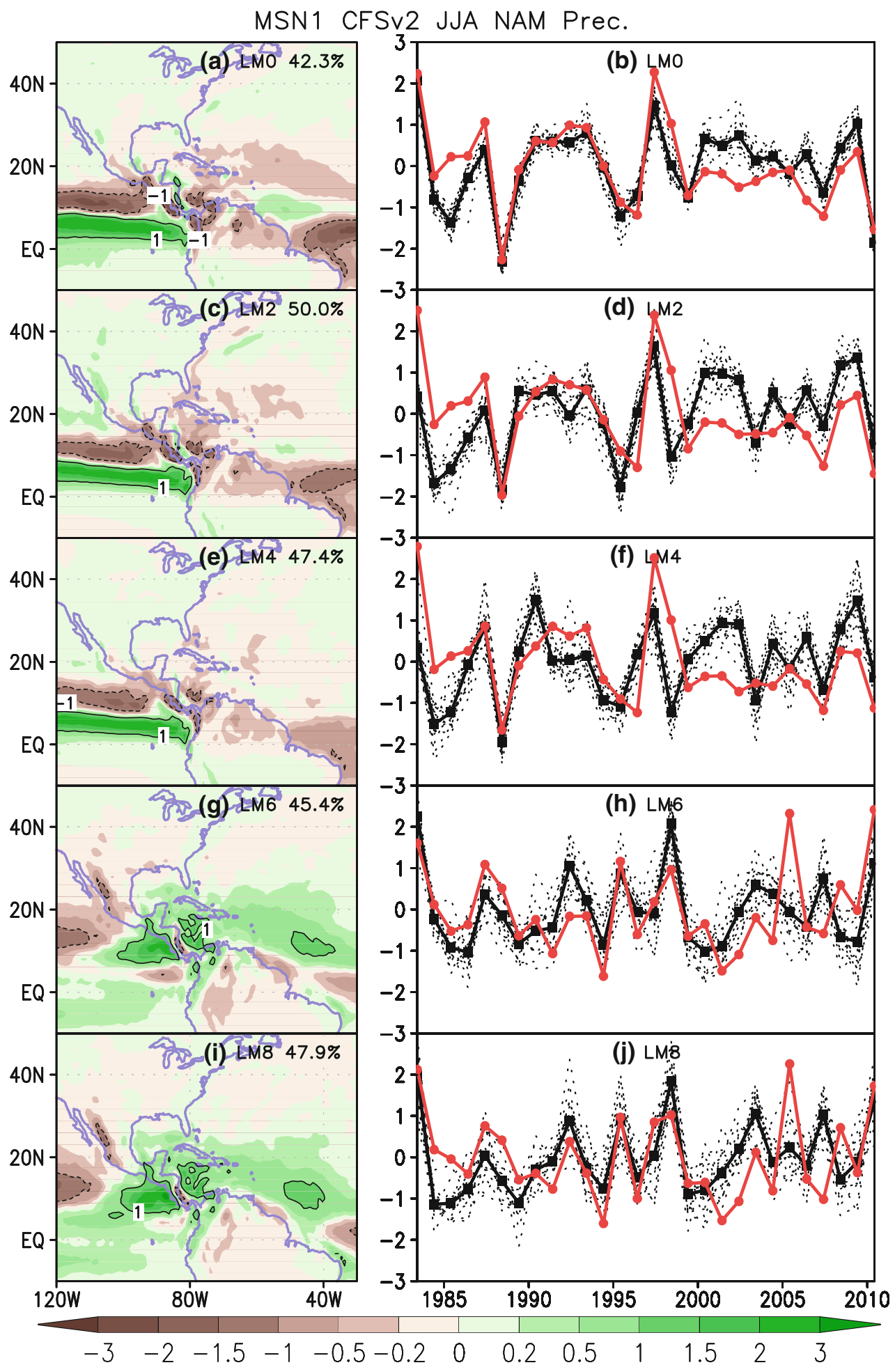

(Fig. 11c), due probably to the downward trend in PC1 (Fig. 1b) and upward trend in SST. The correlations between SST anomaly and the observed PC2 of AFM precipitation (Fig. 11d) present negative correlations in the central and eastern tropical Pacific and positive correlation in the western Pacific, suggesting a possible influence of ENSO. Nevertheless, the most striking and directive impact for the PC2 may come from the tropical Atlantic Ocean with significant correlation along the equatorial Atlantic, which is similar to the SST anomaly distribution in the mature phase of Atlantic Niño (Hu and Huang 2007b). 
Fig. 9 Second MSN EOF modes of the CFSv2 reforecast precipitation $(\mathrm{mm} /$ day) over NAM for lead months of $0,2,4$, 6 , and 8 . In the right panels, the solid black lines and dashed black lines are the PCs of ensemble means and individual members, respectively. The solid red lines represent the PCs that are computed by projecting the observed precipitation upon the MSN EOF2. Only contours 1 and -1 are plotted

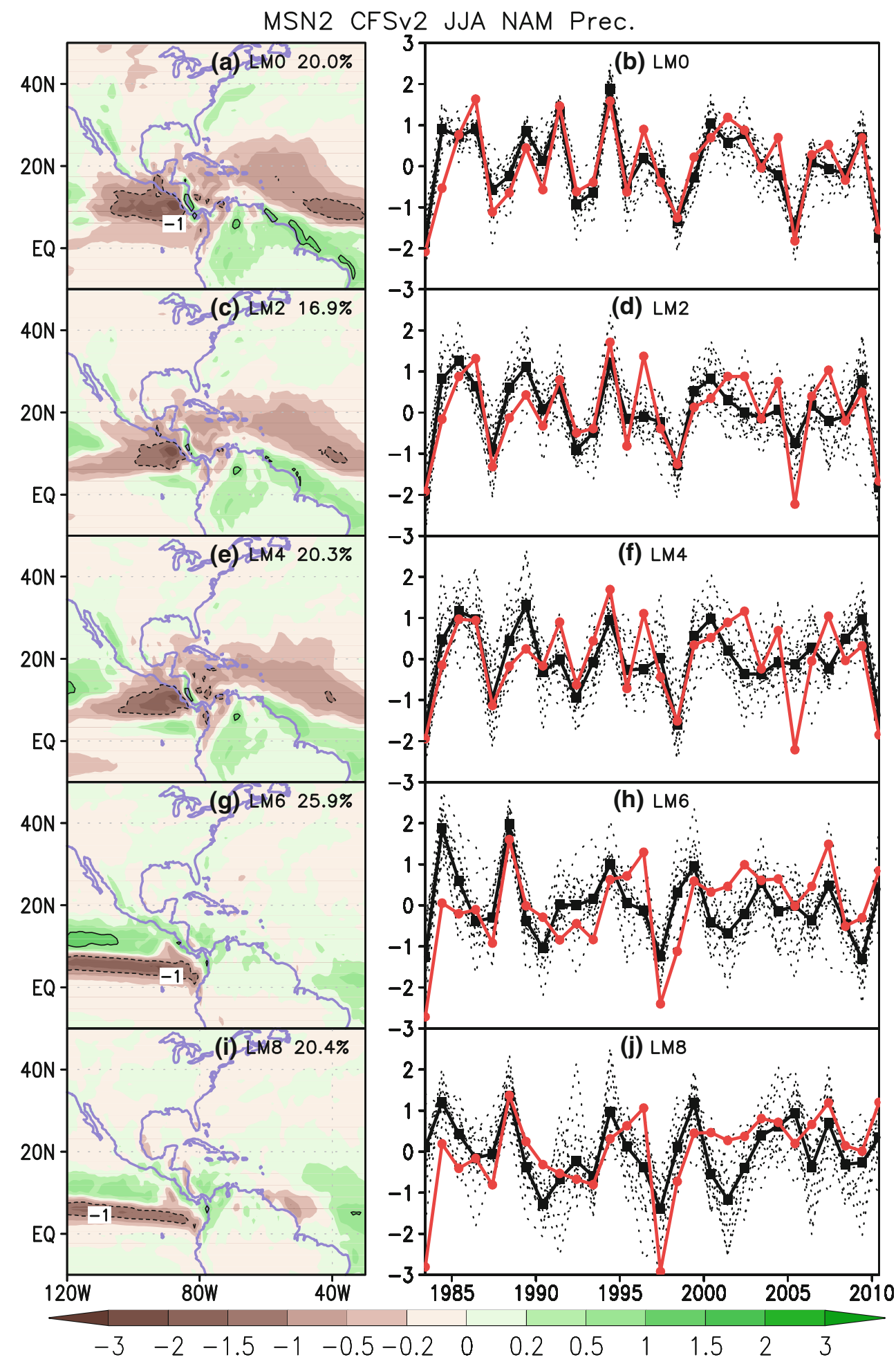

Overall, except that the western coast dipole pattern in AFM is connected with the long-term trend (Figs. 1b, 11c), the major patterns of AIPM, AFM, and NAM precipitation are the generally significant correlations with the tropical Pacific and tropical Atlantic SST variability, which is related to ENSO and Atlantic Niño, respectively. The connections with SST result in the predictability and predictable patterns 
Fig. 10 a Averaged pattern correlation coefficients among ensemble members in conventional EOF1 (short dashed lines), MSN EOF1 (solid lines), and MSN EOF2 (long dashed lines) of NAM. b Correlation coefficients between ensemble mean PCs and projecting PCs (computed by projecting the observed precipitation upon the MSN EOF modes) for MSN PC1 (solid lines) and MSN PC2 (dashed lines) of NAM. The dot black lines denote the correlation coefficients at the 95\% confidence level (Student $t$ test) (a) Cor. coef. among ensemble members for NAM Prec.

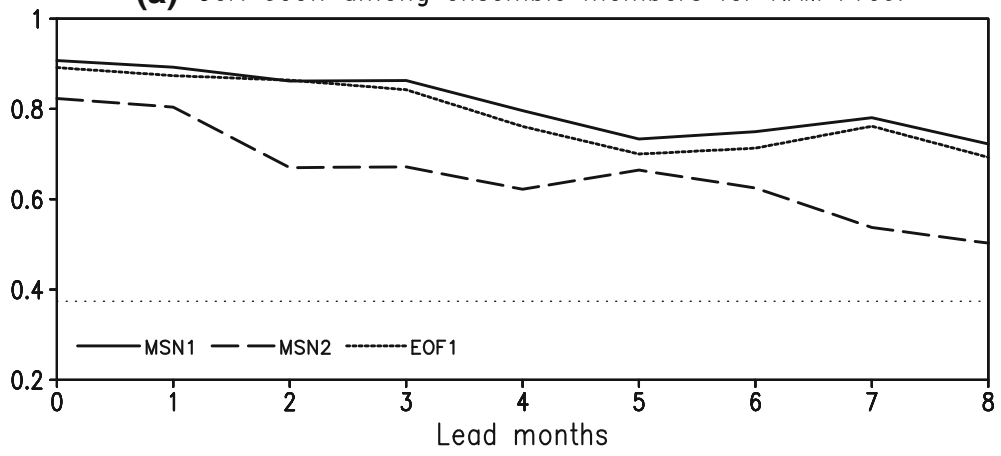

(b) Cor. coef. between Ensemble means and. proj. CMAP for NAM Prec.

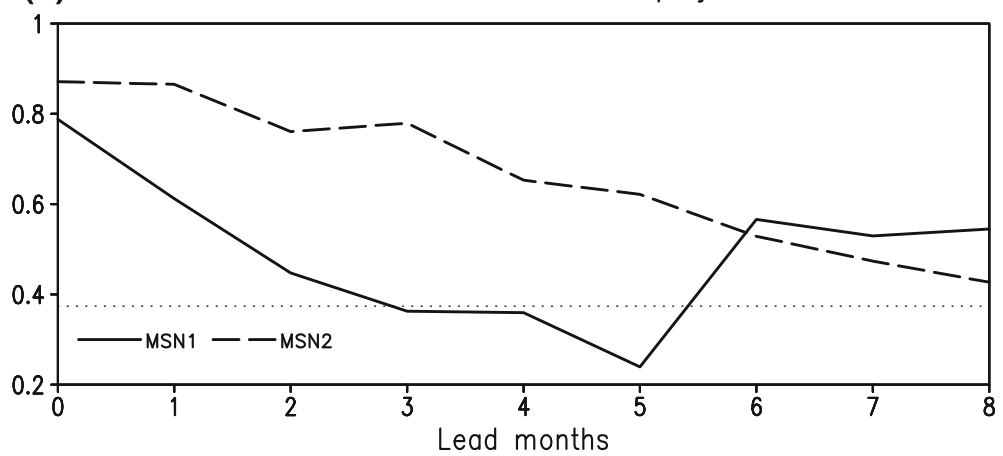

Table 3 MSN EOFs and correlations for NAM precipitation

\begin{tabular}{llllllllll}
\hline & LM0 & LM1 & LM2 & LM3 & LM4 & LM5 & LM6 & LM7 & LM8 \\
\hline MSN1: $\sigma_{M}^{2} / \sigma_{N}^{2}$ & $\mathbf{9 . 5 8}$ & $\mathbf{7 . 9 4}$ & $\mathbf{6 . 1 6}$ & $\mathbf{5 . 9 6}$ & $\mathbf{3 . 8 5}$ & $\mathbf{2 . 7 0}$ & $\mathbf{2 . 9 2}$ & $\mathbf{3 . 3 2}$ & $\mathbf{2 . 5 5}$ \\
MSN2: $\sigma_{M}^{2} / \sigma_{N}^{2}$ & $\mathbf{4 . 5 0}$ & $\mathbf{3 . 8 2}$ & $\mathbf{2 . 0 8}$ & $\mathbf{2 . 0 6}$ & 1.66 & $\mathbf{1 . 9 8}$ & 1.66 & 1.23 & 1.08 \\
MSN1: $R_{\text {mean }, p c 1}$ & $\mathbf{0 . 7 7}$ & $\mathbf{0 . 5 9}$ & $\mathbf{0 . 4 7}$ & $\mathbf{0 . 4 2}$ & $\mathbf{0 . 4 2}$ & 0.19 & 0.15 & 0.15 & 0.15 \\
MSN1: $R_{\text {mean }, p c 2}$ & 0.18 & 0.21 & 0.35 & 0.28 & 0.25 & $\mathbf{0 . 5 7}$ & $\mathbf{0 . 6 5}$ & $\mathbf{0 . 5 1}$ & $\mathbf{0 . 5 0}$ \\
MSN2: $R_{\text {mean, } p 2}$ & $\mathbf{0 . 8 2}$ & $\mathbf{0 . 8 3}$ & $\mathbf{0 . 7 1}$ & $\mathbf{0 . 6 7}$ & 0.64 & 0.33 & 0.16 & 0.25 & 0.26 \\
MSN2: $R_{\text {mean }, p c 1}$ & 0.08 & 0.07 & 0.20 & 0.19 & 0.17 & $\mathbf{0 . 4 8}$ & 0.58 & 0.57 & 0.49 \\
\hline
\end{tabular}

See Table 1 footnote

in these monsoon regions in the CFSv2. Thus, the correctly predicting SST, particularly for the SST in the tropical Pacific and Atlantic oceans, is critical to the seasonable precipitation forecast in these monsoon regions.

It can be seen from Fig. 12, which displays the time series of the observed and CFSv2 reforecast ensemble mean SST anomalies for different leads over Niño1 +2 , Niño3, Niño3.4, and the southeastern tropical Atlantic $\left(30^{\circ} \mathrm{W}-10^{\circ} \mathrm{E}, 20^{\circ} \mathrm{S}-5^{\circ} \mathrm{N}\right.$; SETA) that the CFSv2 can well predict the interannual variability of SST anomalies over Niño1 + 2, Niño3, and Niño3.4 for all leads (Fig. 12a-c). This feature is consistent with the high skill of ENSO prediction by the CFSv2 (Xue et al. 2012). The two leading patterns in AIPM precipitation and in NAM precipitation are significantly correlated to ENSO-like SST anomaly and, as a result, the CFSv2 can well predict these patterns. Namely, the good skill of ENSO prediction benefits the successive prediction of monsoon precipitation.

However, it is noted that in addition to the increase in discrepancy between observed and CFSv2 reforecast SST anomalies with increase in lead time, the systematic warm or cold biases also present and some of them depend on lead time. For example, warm biases are larger for longer lead for Niño1 +2 SST anomalies (Fig. 12a), and the cold biases of Niño3 decrease with increase in lead time. The cold biases of Niño3.4 are less dependent on lead time.

For AFM precipitation anomalies, the weak correlation with SST shown in Fig. 11c suggests that local land surface process may play a more important role than 


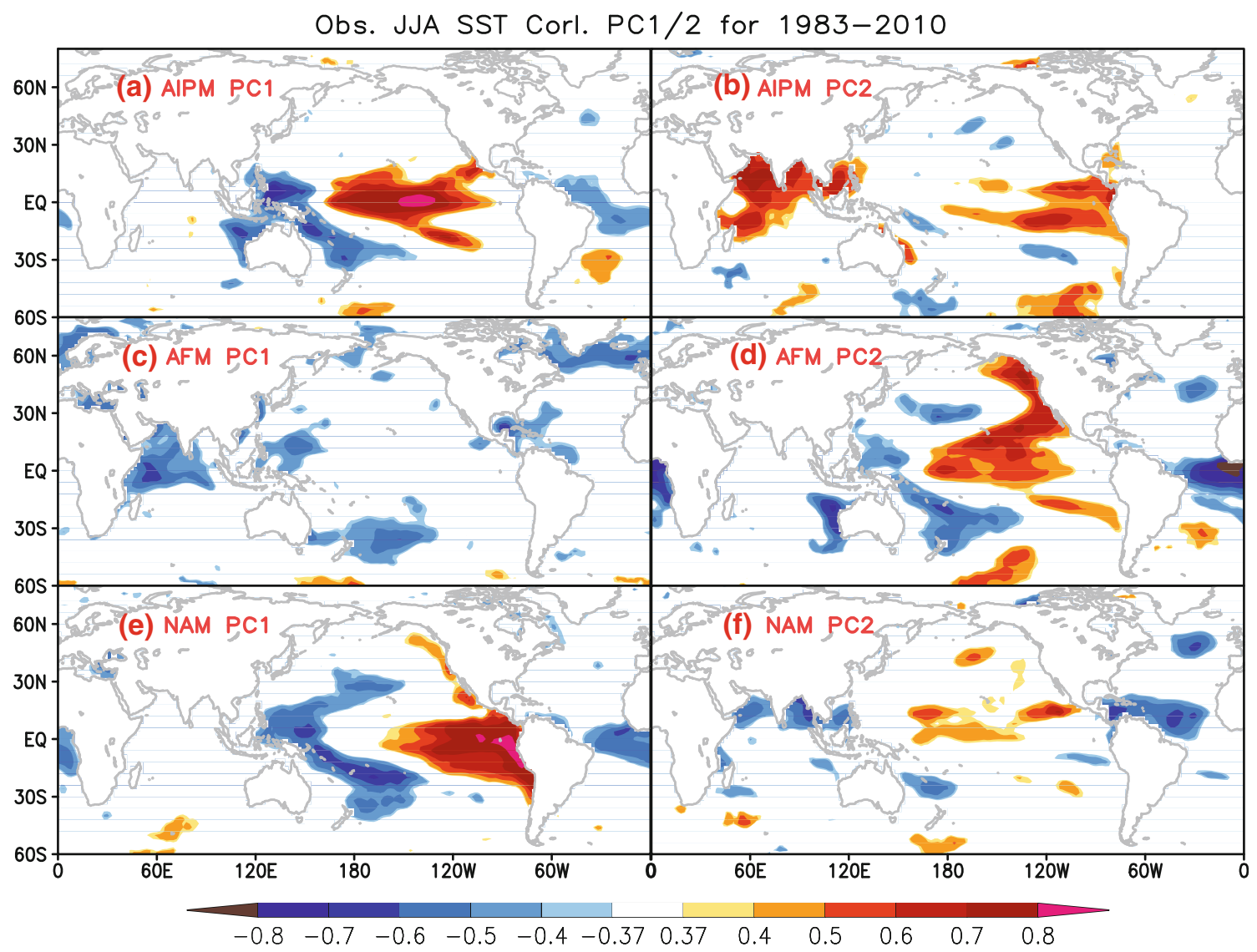

Fig. 11 Correlations between observed SST and the observed PC1 (left panel) and PC2 (right panel) of AIPM (upper panel), AFM (middle panel), and NAM (bottom panel) precipitation. Shaded

ENSO, which may be a reason for the difficult prediction of precipitation in the region. Previous studies have documented that the SST variability over SETA and the land surface process play important roles in AFM precipitation variability (e.g. Folland et al. 1986; Elfatih and Gong 1996). The robust local feedback between precipitation and land surface process in Africa makes the AFM precipitation prediction difficult because of the low skill in predicting land surface condition in the current CFSv2. Although Fig. 11d displays significant positive correlations between SST anomaly in the tropical Atlantic and the PC2 of AFM precipitation anomaly, the CFSv2 has low predictive skill for the SST in the region (Wang et al. 2011; Hu et al. 2012a). The interannual variability of SETA SST exhibits large discrepancy with observations for most of lead time except for LM0-LM3 (Fig. 12d). It is interesting to note that the mean cold biases are larger for shorter leads, implying inaccuracy of initial conditions. All these deficiencies of the CFSv2 may be a factor affecting the predictive skills and predictable patterns in AFM precipitation. denotes the correlation coefficients significantly exceeding the $95 \%$ confidence level (Student $t$ test)

\section{Summary and discussion}

This study has examined the prediction skills and predictable patterns of monsoon precipitation patterns for Northern Hemisphere summer using reforecasts of the NCEP CFSv2. The predictable patterns and their predictive skills of seasonal precipitation anomalies in AIPM, AFM, and NAM, as well as their dependence on lead time are the focus of the present study. Conventional EOF and MSN EOF analyses are used to depict the predictable patterns. Compared with the conventional EOF, the MSN EOF of AIPM, AFM, and NAM precipitation exhibits less spread among the 16 ensemble members for all leads of time, suggesting that the MSN EOF is a better tool for analyzing the predictable pattern. For a precipitation pattern in CFSv2 reforecasts, if the response is consistent and the pattern shows significant correlation with observations, we consider that the pattern is predictable.

The most predictable pattern in AIPM for LM0-LM4 is an equatorial dipole pattern, with maximum negative loadings over the equatorial central-eastern Indian Ocean 
Fig. 12 Time series of the observed (thick black lines) and the CFSv2 reforecast SST (colored lines) over a Niño1 + 2, b Niño3, c Niño3.4, and d SETA $\left(30^{\circ} \mathrm{W}-10^{\circ} \mathrm{E}, 20^{\circ} \mathrm{S}-5^{\circ} \mathrm{N}\right)$

CFSv2 and Obs JJA SST

(a) Nino1+2

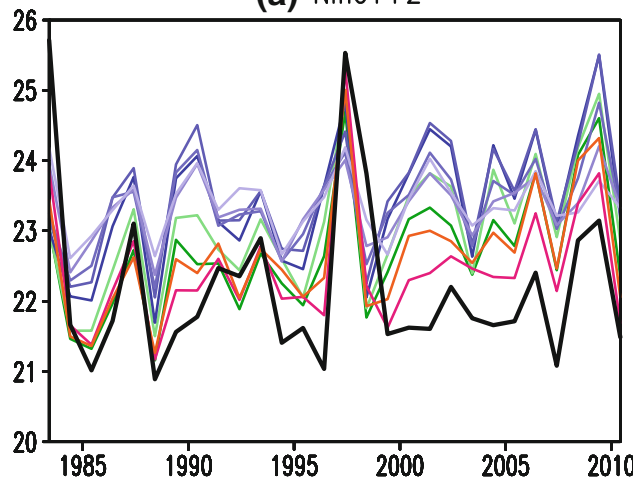

(c) Nino3.4

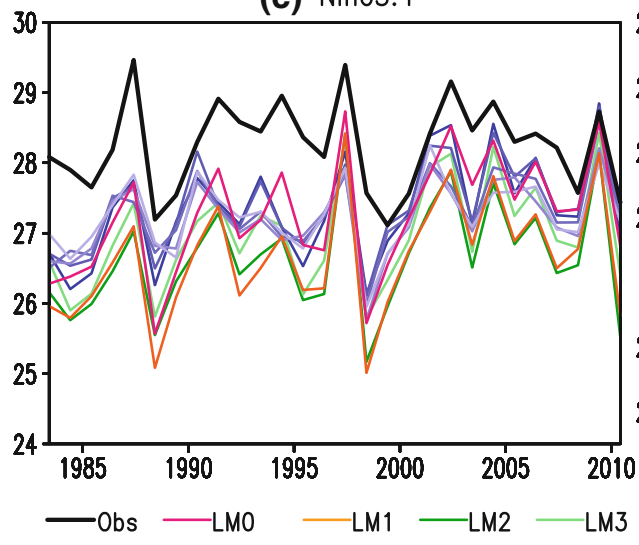

(b) Nino3

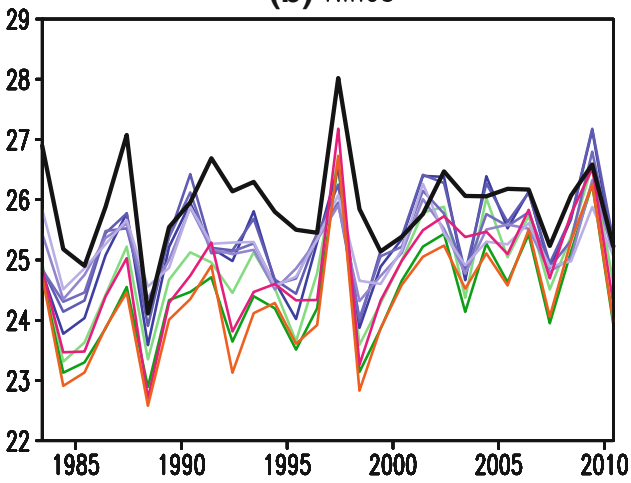

(d) SETA

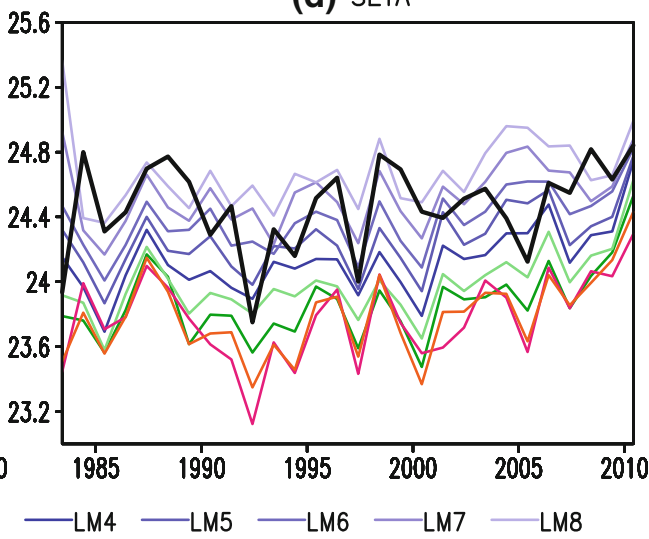

and Indonesia and positive ones over the equatorial western Pacific and from the eastern Bay of Bengal to the Philippines. A tropical western Pacific pattern in AIPM, which is characterized by maximum positive values over the tropical northwestern Pacific and the Philippines and negative values over the northern Indian Ocean, is the second most predictable pattern for LM0-LM3 and the only predictable pattern for LM5-LM8. Namely, the CFSv2 can predict the equatorial dipole pattern 5 months in advance and maintain a good level of prediction skill for the tropical western Pacific pattern except for LM4.

On average, the CFSv2 shows a similar level of prediction skill in NAM. The observed leading mode, characterized by the maximum negative loadings in the tropical eastern Pacific and positive ones around Mexico, the Caribbean Sea, the Guyana Plateau, and the equatorial Atlantic, is the most predicable pattern for LM0-LM4. In addition, the CFSv2 also maintains good level of prediction skill for a pattern characterized by negative loadings in the equatorial and tropical eastern Pacific, the subtropical Pacific east of $110^{\circ} \mathrm{W}$, the Caribbean Sea, and the North Atlantic and positive ones over the subtropical Pacific in $110^{\circ}-120^{\circ} \mathrm{W}$ and the Amazon Plains except for LM4.
Compared with the high level of prediction skill for AIPM and NAM precipitation, the CFSv2 shows lower prediction skills for AFM precipitation.

The leading patterns of observed precipitation variability in AIPM and NAM are significantly correlated with the SST anomalies over the tropical Pacific associated with ENSO. The prediction skills for AIPM and NAM precipitation largely depend on the prediction skill for the tropical Pacific SST. Because of the high skill of CFSv2 in predicting ENSO, the leading variability patterns in AIPM and NAM, related to ENSO, are predictable by the CFSv2. The leading variability patterns of AFM precipitation are mainly associated the long-term trend of SST as well as the tropical Atlantic SST anomalies. The low level of prediction skill for the tropical Atlantic SST anomalies may be associated with the low predictability for AFM precipitation. The results suggest that the ability for successful seasonal forecast of the precipitation variations over the three monsoon regions is critically dependent on the ability to accurately predict SST anomalies in the tropical Pacific and Atlantic, particularly for those associated with ENSO and Atlantic Niño.

It is clear that the predictable patterns and prediction skills for the precipitation in these monsoon regions may be 
model dependent, particularly since the CFSv2 has apparent biases (Kumar et al. 2012; Xue et al. 2012). For example, in the CFSv2 reforecasts, there are clear warm bias of SST over Niño1 +2 and cold bias over Niño3 and Niño3.4. Also, although the CFSv2 reproduces the tropical rain belt and the large precipitation over the subtropical western Pacific several months ahead, wet biases are seen over the southern slope of the Tibetan Plateau, the Indian Ocean, the tropical western and eastern Pacific, and the tropical Atlantic and dry biases over the Bay of Bengal, the South China Sea, the Indian subcontinent, and the Amazon Plains (not shown). These biases may largely affect the predictable patterns and prediction skills for the precipitation in these monsoon regions, which deserves further investigations.

Acknowledgments This study was jointly supported by the National Natural Science Foundation of China (41205059 and 41221064), the Special Fund for Public Welfare Industry (Meteorology) (GYHY201206017), the International S\&T Cooperation Project of the Ministry of Science and Technology of China (2009DFA21430), the Basic Research Fund of Chinese Academy of Meteorological Sciences (2012Z001), Sun Yat-sen University "985" Project Phase 3, and the NOAA-CMA Bilateral Program.

Open Access This article is distributed under the terms of the Creative Commons Attribution License which permits any use, distribution, and reproduction in any medium, provided the original author(s) and the source are credited.

\section{References}

Adams DK, Comrie AC (1997) The North American monsoon. Bull Am Meteor Soc 78:2197-2213

Allen MR, Smith LA (1997) Optimal filtering in singular spectrum analysis. Phys Lett 234:419-428

Barlow M, Nigam S, Berbery EH (1998) Evolution of the North American monsoon system. J Clim 11:2238-2257

Elfatih AB, Gong CL (1996) Dynamics of wet and dry years in West Africa. J Clim 9:1030-1042

Folland CK, Palmer TN, Parker DE (1986) Sahel rainfall and worldwide sea temperatures, 1901-85. Nature 320:602-607

Gao H, Yang Y, Kumar A, Hu Z-Z, Huang B, Li Y, Jha B (2011) Variations of the East Asian Mei-yu and simulations and prediction by the NCEP Climate Forecast System. J Clim 24:94-108. doi:10.1175/2010JCLI3540

Hu Z-Z, Huang B (2007a) The predictive skill and the most predictable pattern in the tropical Atlantic: the effect of ENSO. Mon Weather Rev 135:1786-1806

Hu Z-Z, Huang B (2007b) Physical processes associated with tropical Atlantic SST gradient during the anomalous evolution in the southeastern ocean. J Clim 20:3366-3378

Hu Z-Z, Kumar A, Huang B, Wang W, Zhu J, Wen C (2012a) Prediction skill of monthly SST in the North Atlantic Ocean in NCEP Climate Forecast System version 2. Clim Dyn. doi: 10.1007/s00382-012-1431-z (published online)

Hu Z-Z, Kumar A, Jha B, Wang W, Huang B, Huang B (2012b) An analysis of warm pool and cold tongue El Niños: air-sea coupling processes, global influences, and recent trends. Clim Dyn 38(9-10):2017-2035. doi:10.1007/s00382-011-1224-9

Huang B (2004) Remotely forced variability in the tropical Atlantic Ocean. Clim Dyn 23:133-152

Jiang XW, Yang S, Li YQ Liu XW, Zuo ZY, Jha B (2012) Seasonalto-interannual prediction of the Asian summer monsoon in the NCEP Climate Forecast System Version 2. J Clim. doi: 10.1175/JCLI-D-12-00437.1

Jiang XW, Yang S, Li YQ, Kumar A, Wang WQ, Gao ZT (2013) Dynamical prediction of the East Asian winter monsoon by the NCEP Climate Forecast System. J Geophys Res 118:1312-1328

Kim H-M, Webster PJ, Curry JA (2012) Seasonal prediction skill of ECMWF system 4 and NCEP CFSv2 retrospective forecast for the northern hemisphere winter. Clim Dyn. doi:10.1007/s0038 2-012-1364-6

Kumar A, Chen M, Zhang L, Wang W, Xue Y, Wen C, Marx L, Huang B (2012) An analysis of the non-stationarity in the bias of sea surface temperature forecasts for the NCEP Climate Forecast System (CFS) Version 2. Mon Weather Rev 140:3003-3016

Lau K-M, Kim K-M, Yang S (2000) Dynamical and boundary forcing characteristics of regional components of the Asian summer monsoon. J Clim 13:2461-2482

Liang JY, Yang S, Hu ZZ, Huang B, Kumar A, Zhang Z (2009) Predictable patterns of the Asian and Indo-Pacific summer precipitation in the NCEP CFS. Clim Dyn 32:989-1001

Liu X, Yang S, Kumar A, Weaver S, Jiang X (2012) Diagnostics of sub-seasonal prediction biases of the Asian summer monsoon by the NCEP Climate Forecast System. Clim Dyn (in press)

Meehl GA, Arblaster JM (1998) The Asian-Australian monsoon and El Niño-Southern Oscillation in the NCAR Climate System Model. J Clim 11:1356-1385

Molteni $F$ et al (2011) The new ECMWF seasonal forecast system (system 4). ECMWF Technical Memorandum 656

Palmer T et al (2004) Development of a European multimodel ensemble system for seasonal-to-interannual prediction (DEMETER). Bull Am Meteorol Soc 85:853-872

Rowell DP, Folland CK, Maskell K, Ward MN (1995) Variability of summer rainfall over tropical North Africa (1906-92): observations and modeling. Quart J R Meteorol Soc 121:669-704

Saha S et al (2006) The NCEP climate forecast system. J Clim 19:3483-3517

Saha S et al (2010) The NCEP climate forecast system reanalysis. Bull Am Meteorol Soc 90:1015-1057

Saha $S$ et al (2012) The NCEP climate forecast system version 2. J Clim. http://cfs.ncep.noaa.gov/cfsv2.info/CFSv2_paper.pdf

Smith TM, Reynolds RW (2004) Improved extended reconstruction of SST (1854-1997). J Clim 17:2466-2477

Tang M, Reiter ER (1984) Plateau monsoons of the Northern Hemisphere: a comparison between North America and Tibet. Mon Weather Rev 112:617-637

Venzke S, Allen MR, Sutton RT, Rowell DP (1999) The atmospheric response over the North Atlantic to decadal changes in sea surface temperature. J Clim 12:2562-2584

Wang B, Ding Q (2008) The global monsoon: major modes of annual variations in the tropics. Dyn Atmos Ocean. Special issue 2. doi: 10.1016/j.dynatmoce.2007.05.002

Wang G, Kleeman R, Smith N, Tseitkin F (2001) The BMRC coupled general circulation model ENSO forecast system. Mon Weather Rev 130:975-991

Wang W, Chen M, Kumar A (2011) An assessment of the CFS real time seasonal forecasts. Weather Forecast 25:950-969

Weaver SJ, Wang W, Chen M, Kumar A (2011) Representation of MJO variability in the NCEP climate forecast system. J Clim 24:4676-4694 
Webster PJ, Yang S (1992) Monsoon and ENSO: selectively interactive systems. Quart J R Meteorol Soc 118:877-926

Xie P, Arkin PA (1997) Global precipitation: a 17-year monthly analysis based on gauge observations, satellite estimates, and numerical model outputs. Bull Am Meteorol Soc 78:2539-2558

Xue Y, Chen M, Kumar M, Hu Z-Z, Wang W (2012) Prediction skill and bias of tropical Pacific sea surface temperatures in the NCEP Climate Forecast System version 2. J Clim (revised)

Yang S, Zhang Z, Kousky VE, Higgins RW, Yoo SH, Liang J, Fan Y (2008) Simulations and seasonal prediction of the Asian summer monsoon in the NCEP Climate Forecast System. J Clim 21:3755-3775

Yang DJ, Tang YM, Zhang YC, Yang XQ (2012) Information-based potential predictability of the Asian summer monsoon in a coupled model. J Geophys Res 117:D03119. doi: 10.1029/2011JD016775

Yuan X, Wood EF, Luo L, Pan M (2011) A first look at Climate Forecast System version 2 (CFSv2) for hydrological seasonal prediction. Geophys Res Lett 38:L13402 